\title{
Highly Stereoselective Synthesis of Aristeromycin through Dihydroxylation of 4-Aryl-1-azido-2-cyclopentenes
}

Takauki Ainai, Yong-Gang Wang, Yuko Tokoro, and Yuichi Kobayashi*

Department of Biomolecular Engineering, Tokyo Institute of Technology, 4259 Nagatsuta-cho, Midori-ku, Yokohama 226-8501, Japan

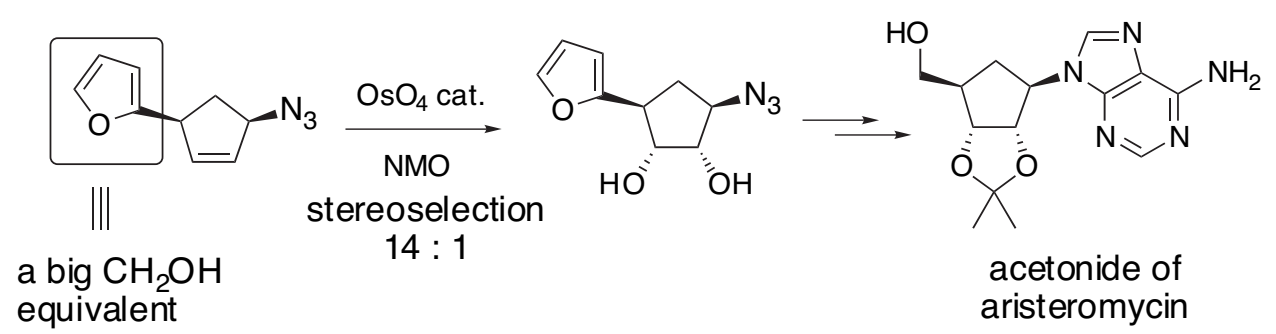

1. General Information

S2

2. ${ }^{1} \mathrm{H}$ NMR spectra for compounds

$6 a-c, 7 a-c, 11,12,15,16$, and 2 S3-S13 
General Information. Infrared (IR) spectra are reported in wave numbers $\left(\mathrm{cm}^{-1}\right)$. The ${ }^{1} \mathrm{H}$ $\operatorname{NMR}(300 \mathrm{MHz})$ and ${ }^{13} \mathrm{C} \mathrm{NMR}(75 \mathrm{MHz})$ spectra were measured in $\mathrm{CDCl}_{3}$ using $\mathrm{SiMe}_{4}(\delta=0$ ppm) and the center line of $\mathrm{CDCl}_{3}$ triplet $(\delta=77.1 \mathrm{ppm})$ as internal standards, respectively. Racemic acetate $9,{ }^{1 \mathrm{a}, \mathrm{b}}(1 \mathrm{R}, 3 \mathrm{~S})-\mathbf{9}^{1 \mathrm{c}, \mathrm{d}}\left([\alpha]^{20}{ }_{\mathrm{D}}=+75\left(\mathrm{c} 1.02, \mathrm{CHCl}_{3}\right)\right)$ of $>95 \%$ ee (checked by the MTPA method), and cyclopentenols $\mathbf{1 0 b ^ { 2 }}$ and $10 c^{2}$ were prepared according to the procedures. Routinely, organic extracts were dried over $\mathrm{MgSO}_{4}$ and concentrated by using a rotary evaporator to afford residues, which were purified by chromatography on silica gel. Caution: $\mathrm{OsO}_{4}$ used for the dihydroxylation of cyclopentenes $\mathbf{6 a - c}$ is a highly toxic reagent.

\section{References}

(1) (a) Deardorff, D. R.; Myles, D. C.; MacFerrin, K. D. Tetrahedron Lett. 1985, 26, 5615-5618. (b) Deardorff, D. R.; Myles, D. C. In Organic Syntheses; Freeman, J. P., Ed.; Wiley: New York, 1993; Collect. Vol. 8, pp 13-16.

(c) Sugai, T.; Mori, K. Synthesis 1988, 19-22. (d) Laumen, K.; Schneider, M. P. J. Chem. Soc., Chem. Commun. 1986, 1298-1299.

(2) Ainai, T.; Ito, M.; Kobayashi, Y. Tetrahedron Lett. 2003, 44, 3983-3986. 

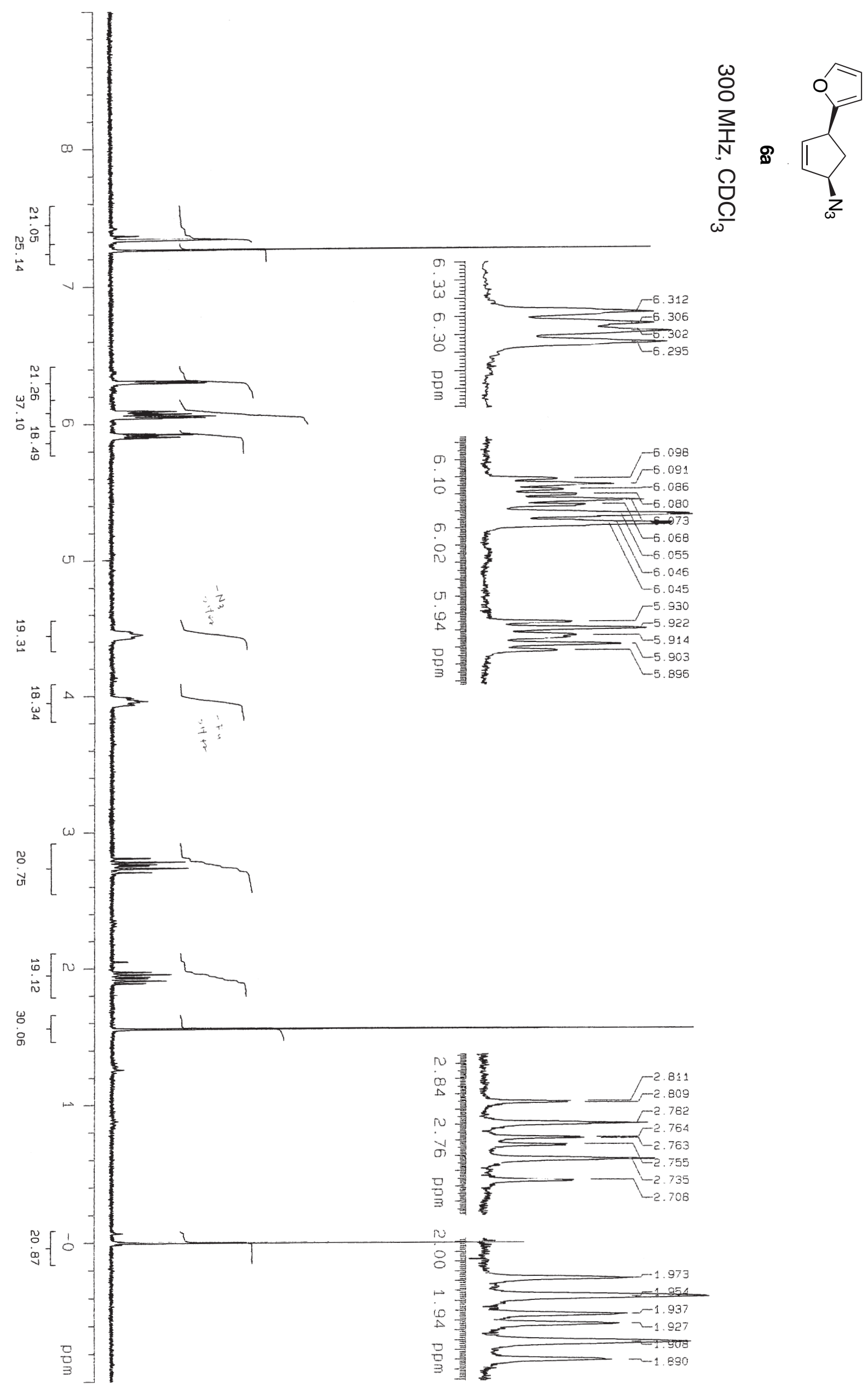


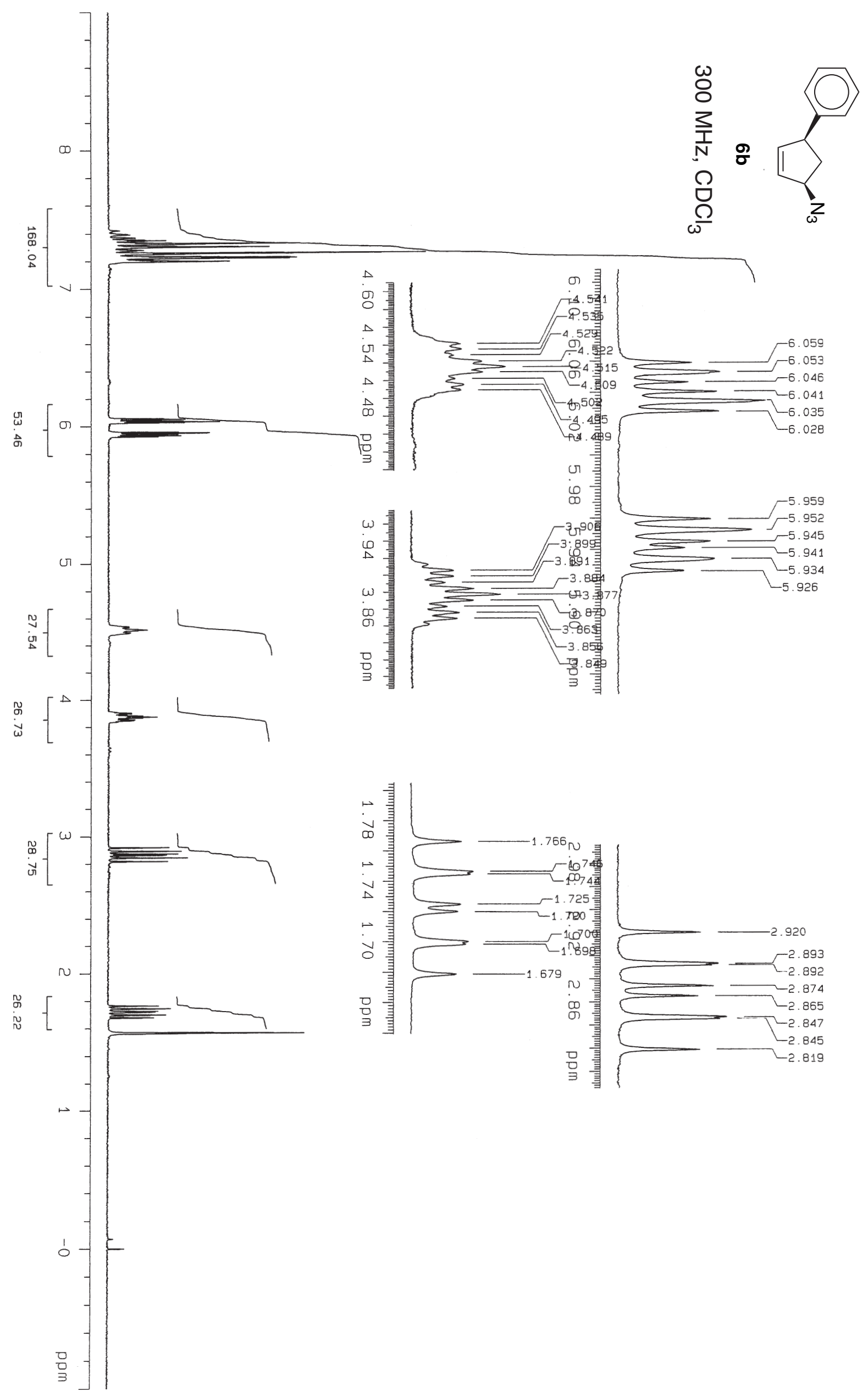



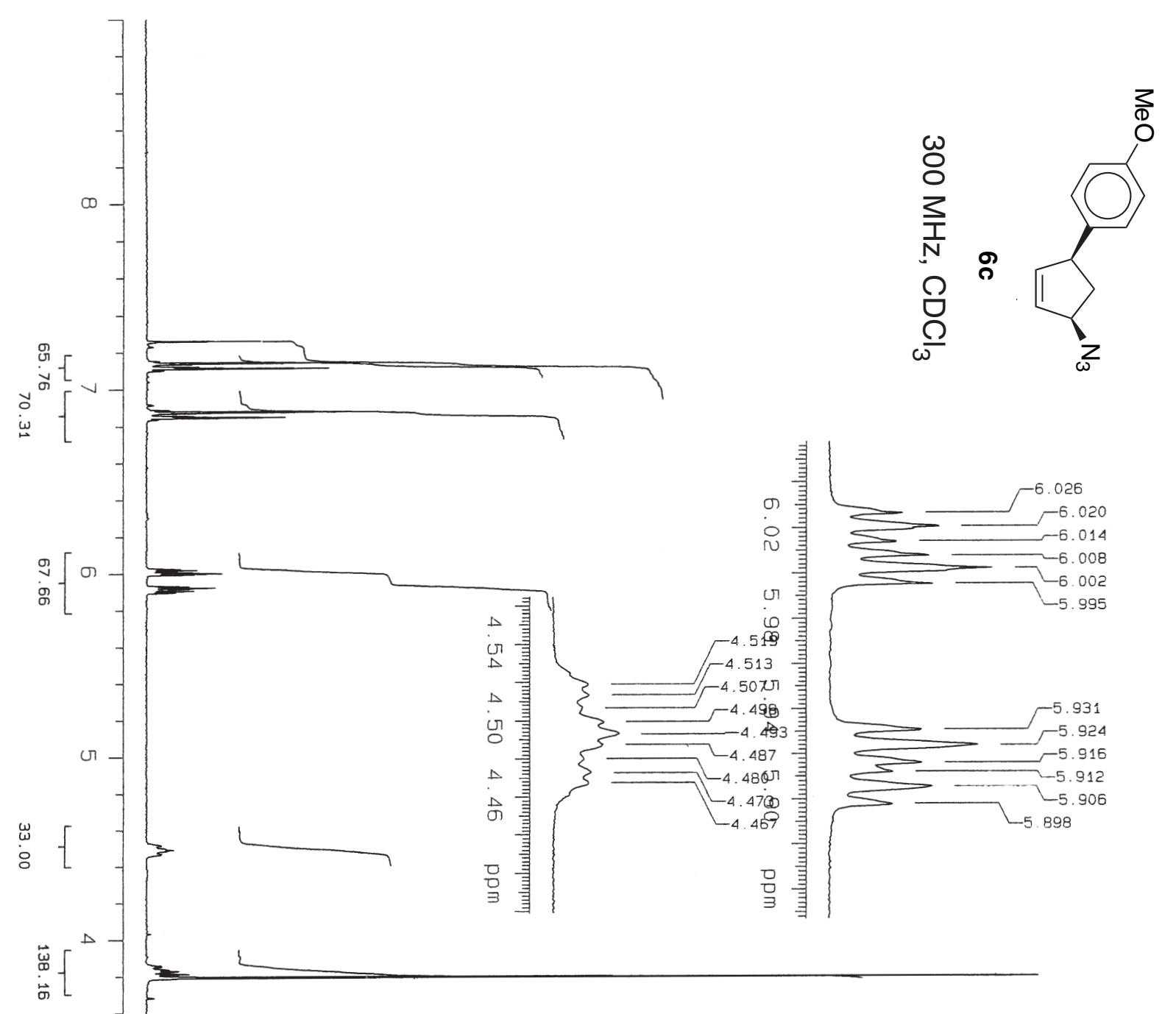


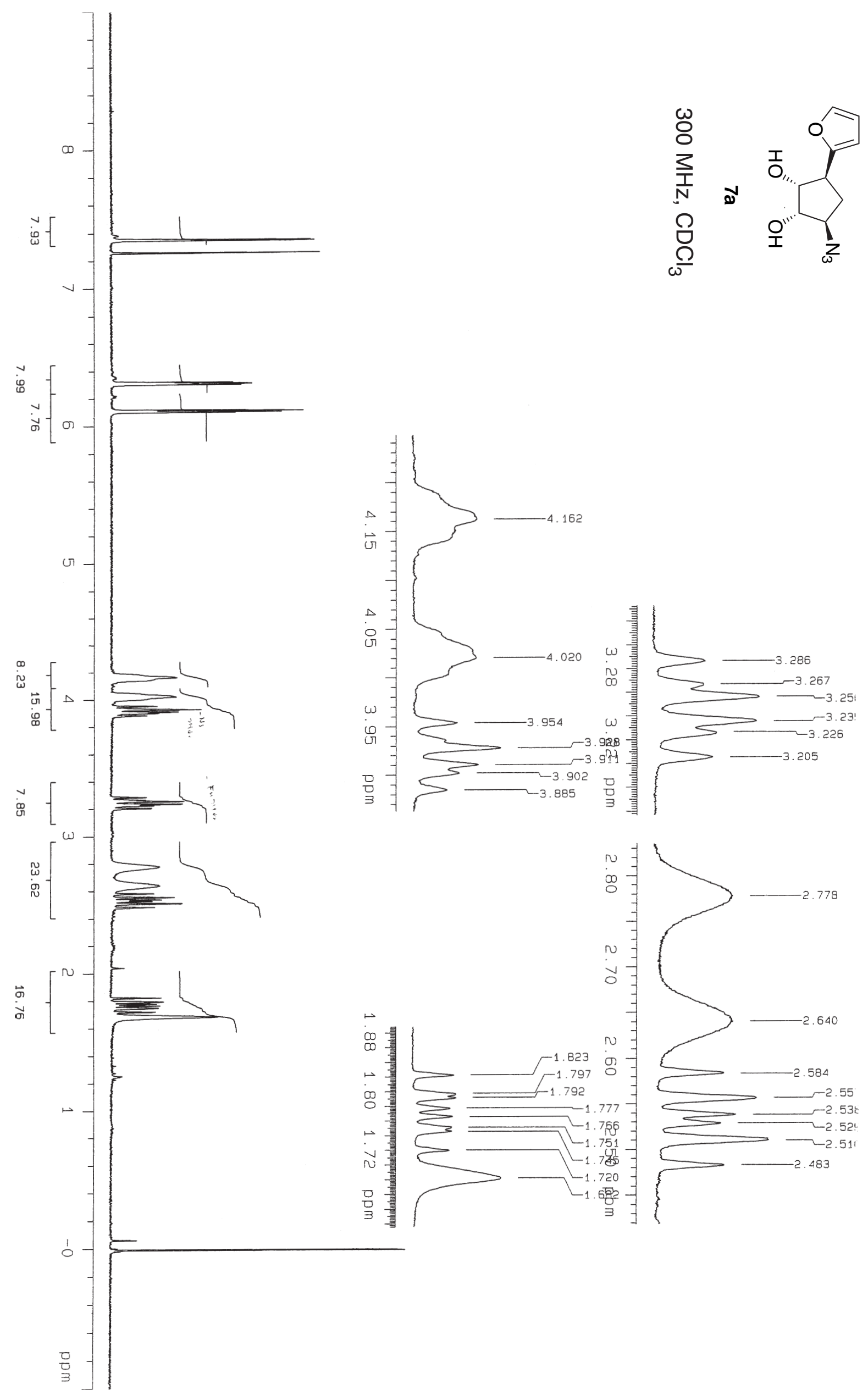




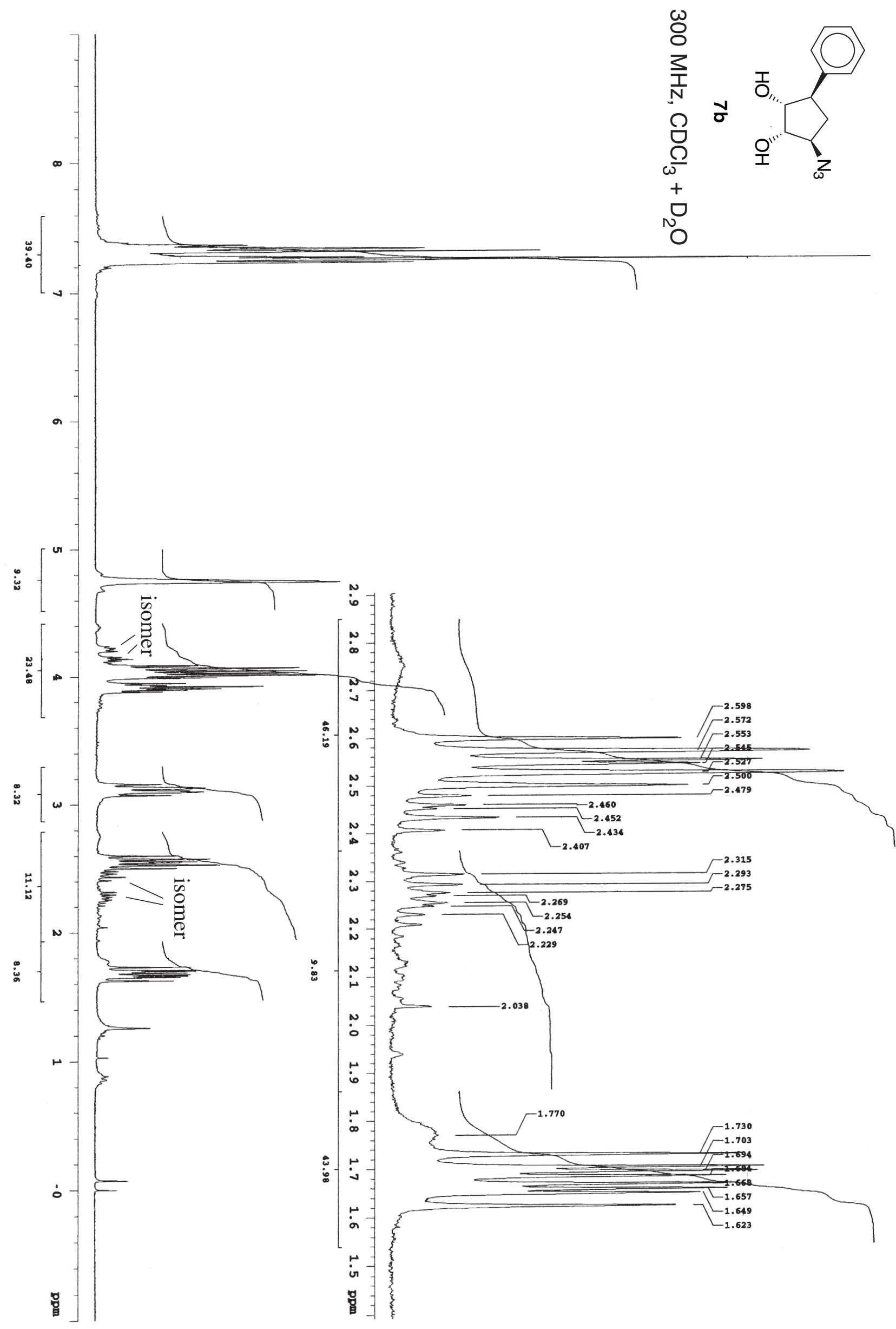




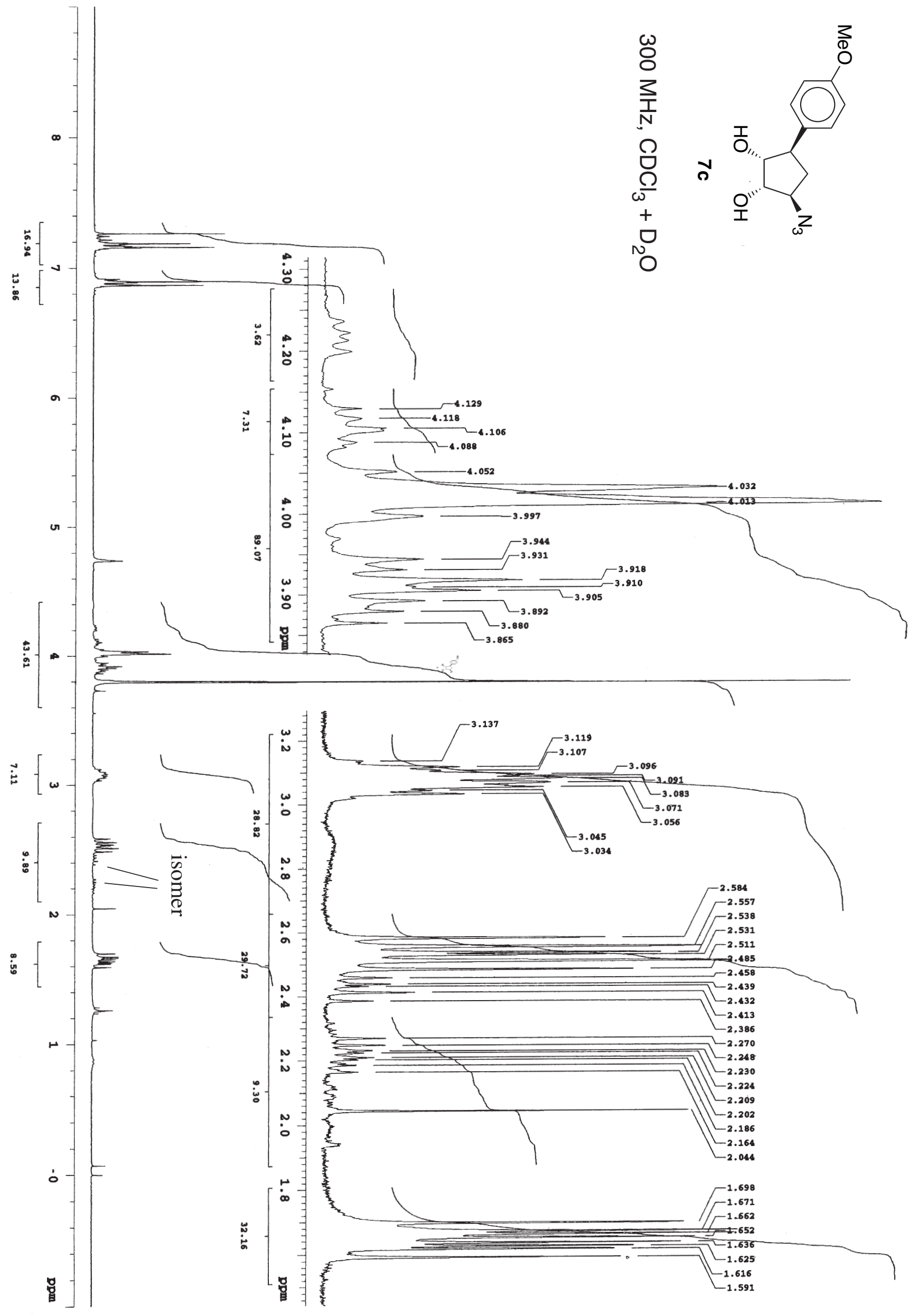




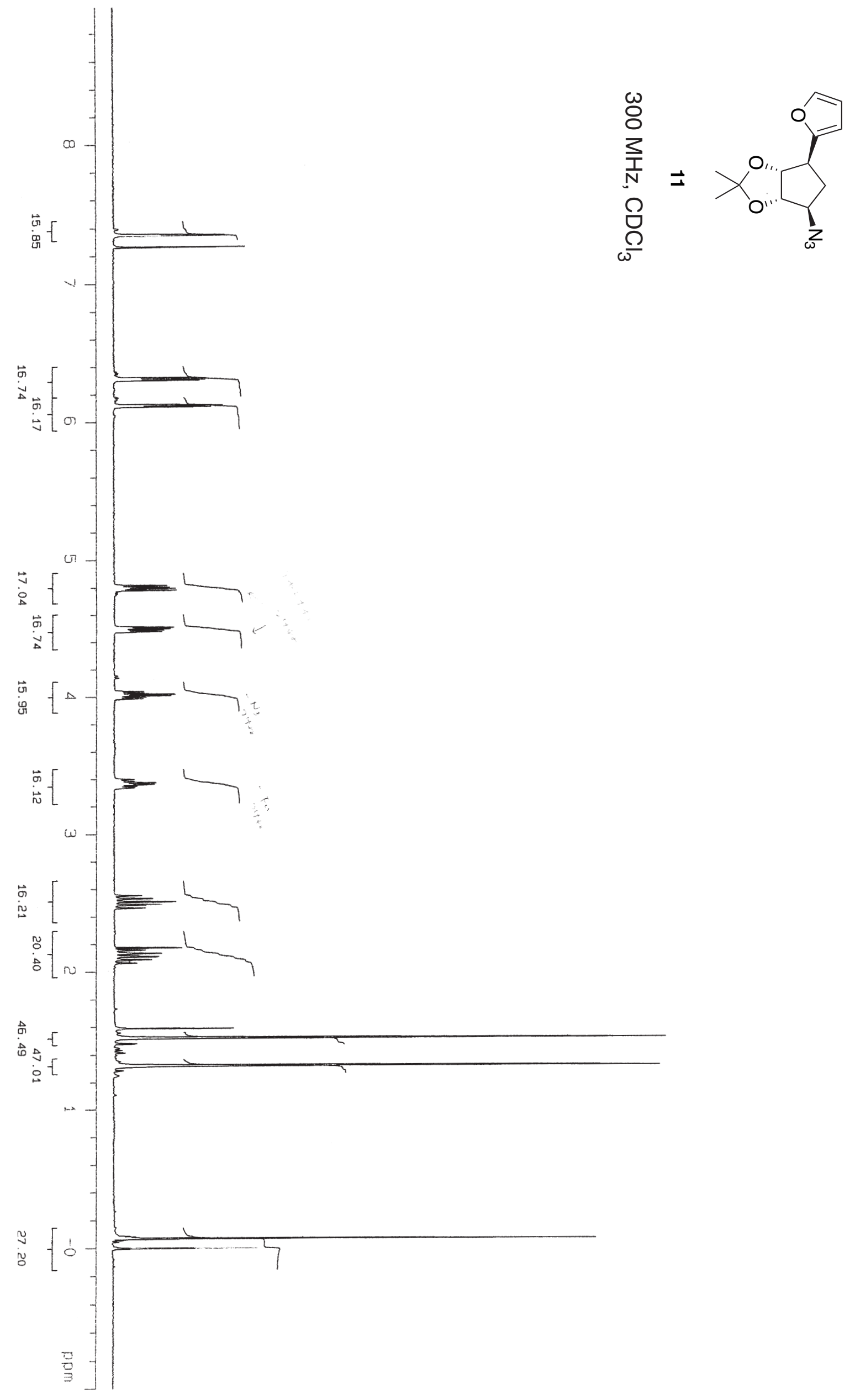




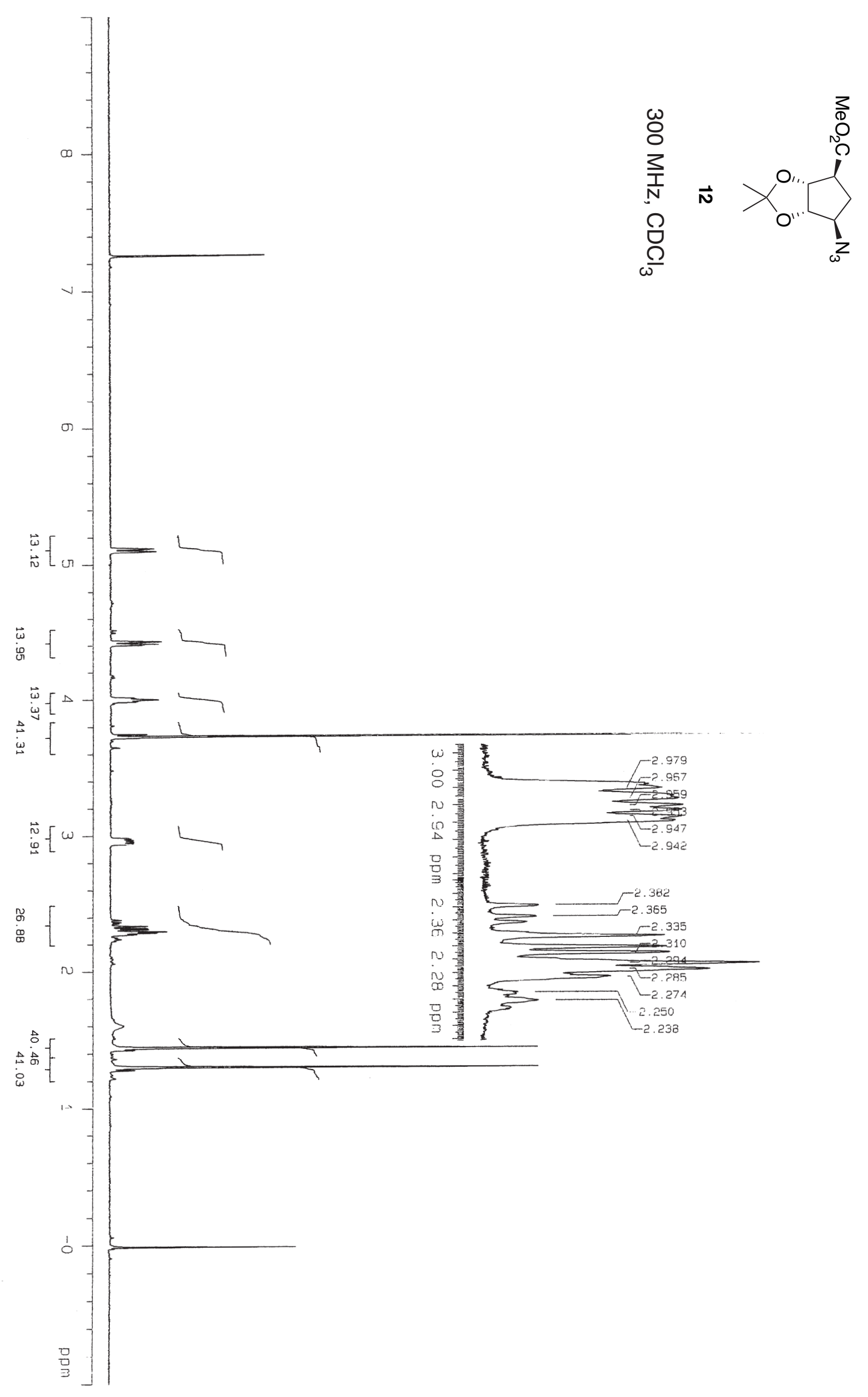




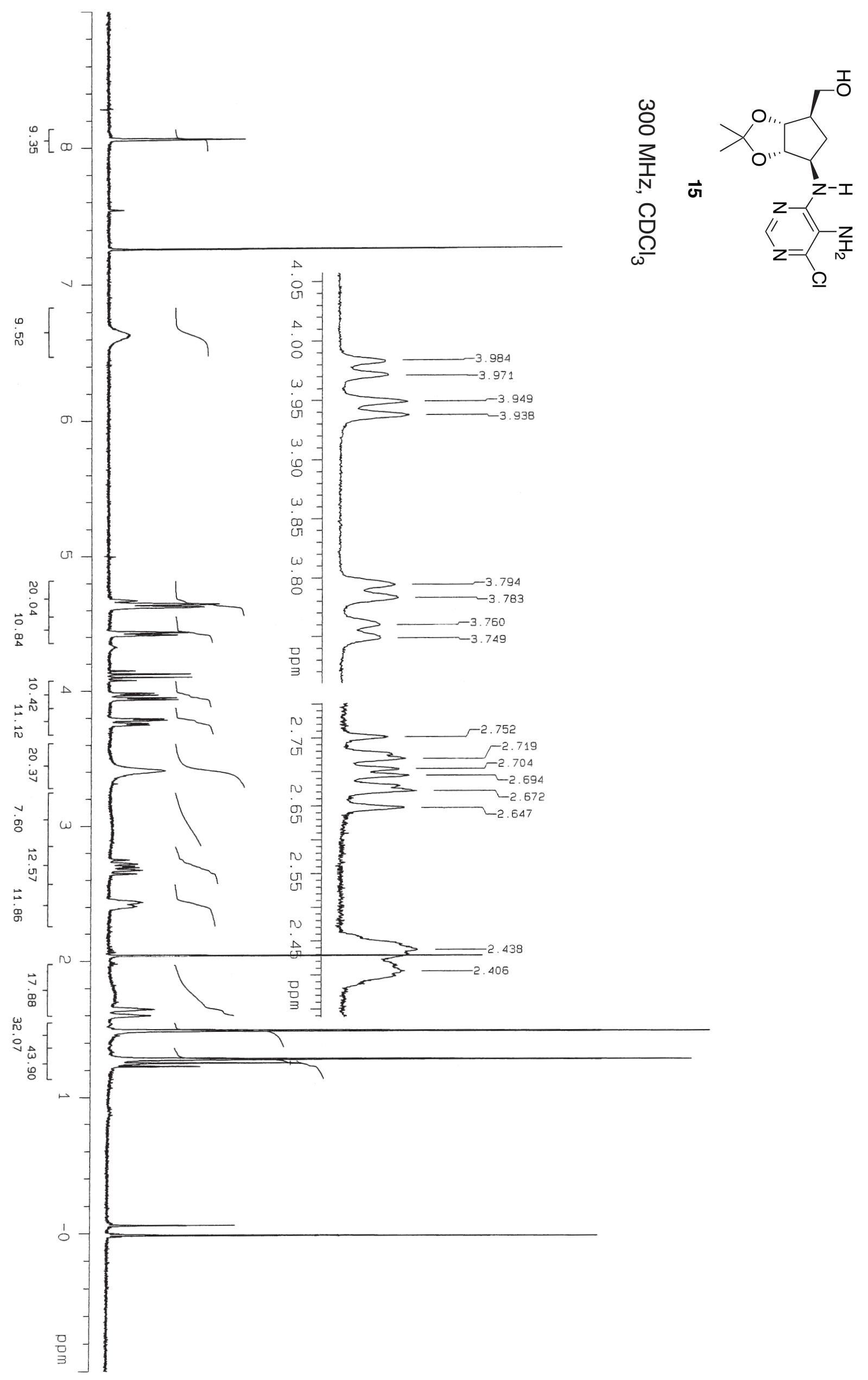




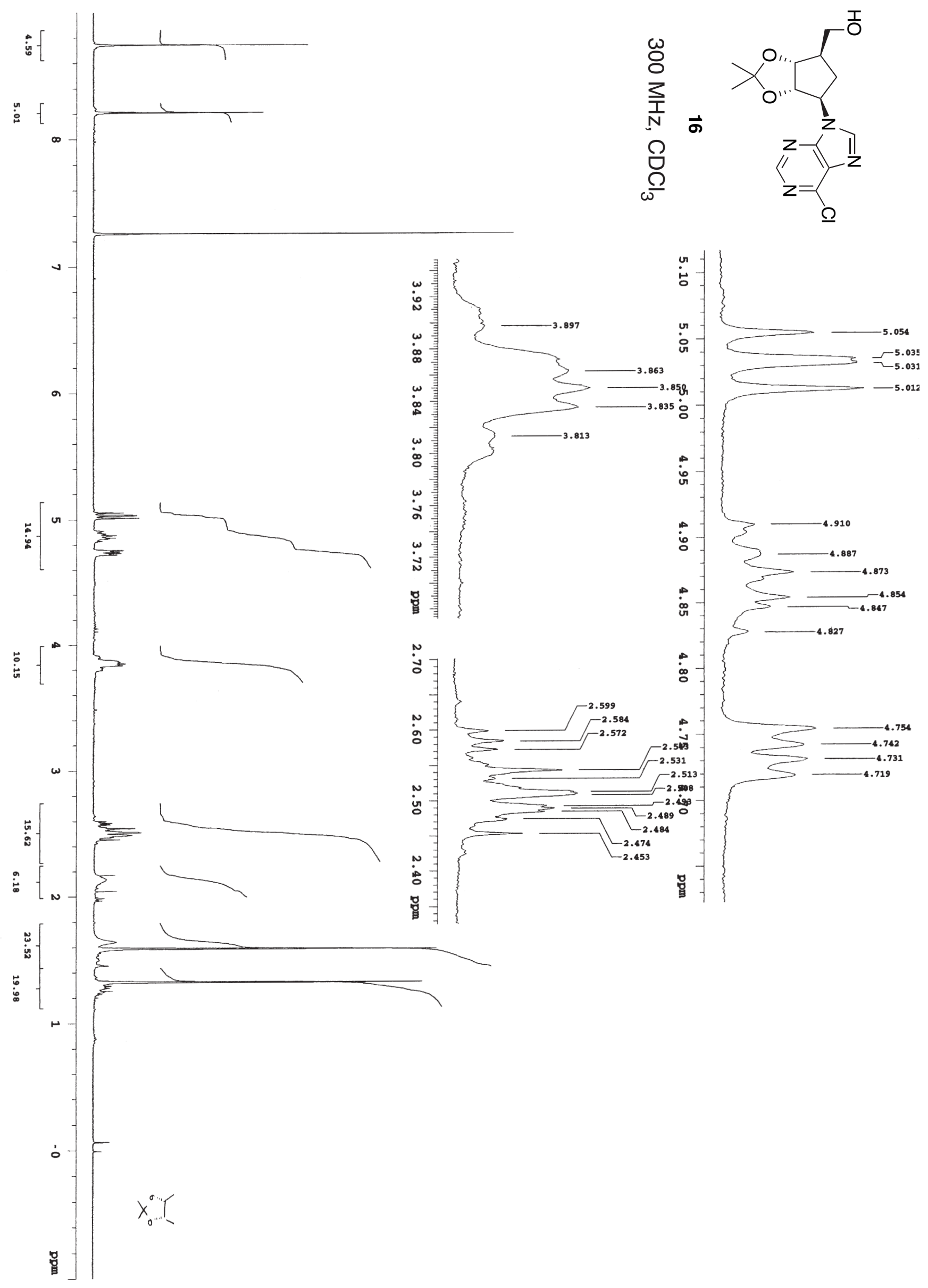




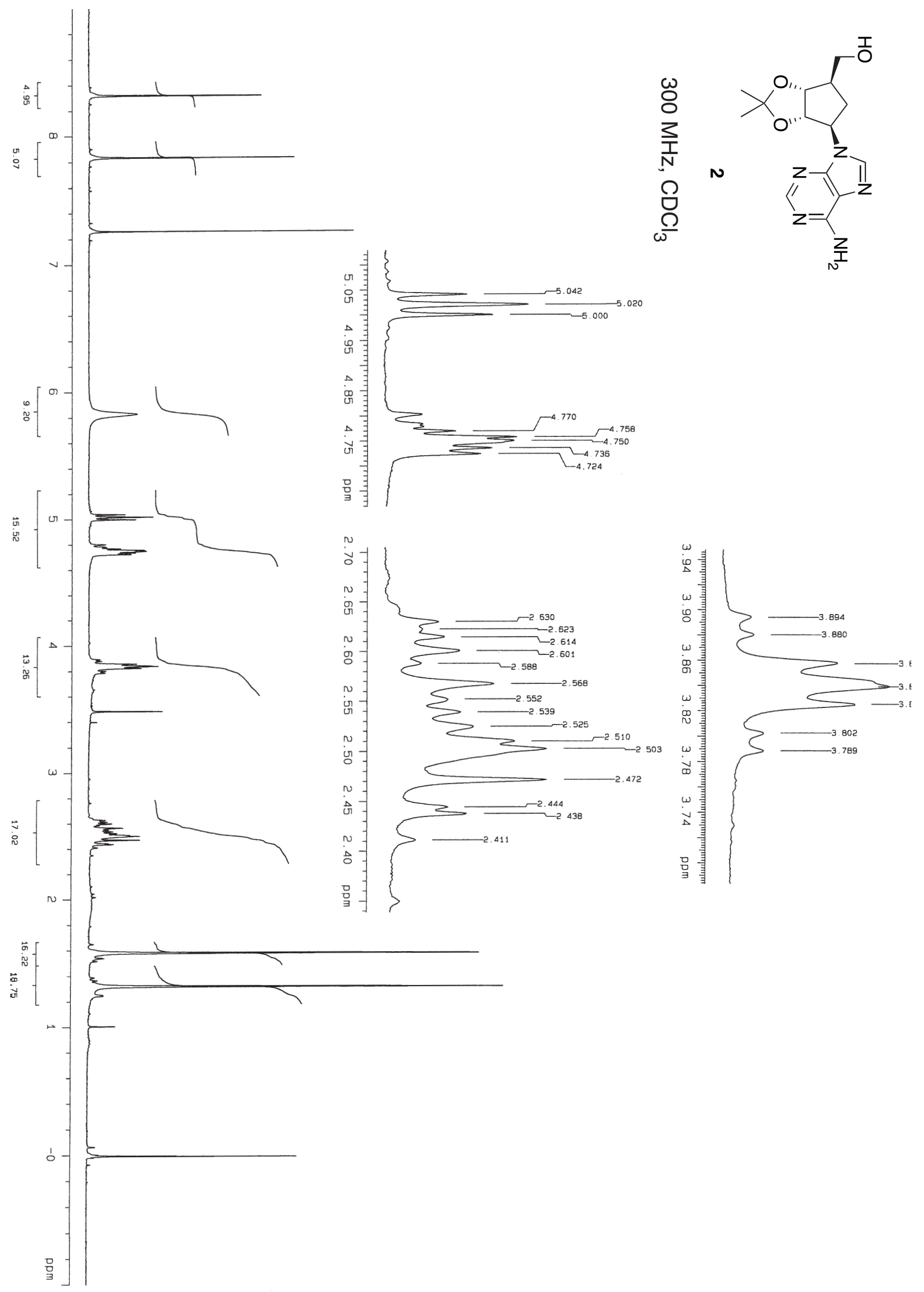

